\title{
高中音乐视唱练耳教学研究分析
}

\author{
程博 \\ 吉林省辉南县第一中学 \\ DOI:10.32629/jief.v2i4.1311
}

[摘 要] 视唱练耳是学习音乐的基础学科之一, 属于识谱的一个技能训练, 可以充分的调动学生的视觉、听觉、乐感, 并通过这些感觉来积 极的训练识谱。通过视唱练耳, 可以有效的帮助学生积累素材、提高学生的音乐鉴赏能力, 对学生音乐的感受理解和演奏方面都有着很大的 帮助。但是在传统高中阶段, 由于学生身上肩负着各种学习压力, 对学生视唱练耳方面的技能没有充分的训练。新课改重视学生的综合素质, 高中音乐的地位也得到了不断提高。笔者对高中音乐的基础学科视唱练耳进行了研究分析, 并提出了相应的教学方法。

[关键词] 高中音乐; 视唱练耳; 教学; 研究分析

中图分类号: G633.951 文献标识码: A

视唱练耳主要是考验学生对音高、节奏的感知能力和记忆能力, 教 学目标也是提高这一方面的感知记忆能力, 视唱主要注重阅读简谱或者 五线谱, 然后将其唱出来, 而练耳主要注重对曲谱或者歌曲的分析和感 知, 而且分析感知到的音乐信息越丰富越具体, 就意味着学生的音乐水 平越高。视唱练耳完全可以通过后天的努力训练而成, 因此为了提高学 生的视唱练耳水平能力, 教师可以采用以下方法来进行视唱练耳教学。

\section{1 尊重学生的主体地位, 加强学生在课堂中的训练}

在音乐当中, 不管是那些唱歌好, 也就是俗称 “五音很全” 的学生, 还是那些耳朵感知力好的学生, 他们都经历了不断的训练。而在传统教 学过程中, 在整个课堂教学中充斥了教师讲课的声音, 而没有学生练习 或者音乐的声音, 削弱了学生的训练, 不利于学生视唱练耳水平提高。 因此教师需要充分尊重学生的主体地位, 加强学生的课堂视唱练耳训练。

比如在《祖国颂歌》这一课的教学过程中, 教师可以先大体上简单 的讲解关于群众歌曲和艺术歌曲的知识, 剩下的时间再去引导学生进行 训练。教师可以将《我和我的祖国》的歌词和音乐展示出来, 让学生倾 听, 然后让学生说出关于乐曲的感受, 然后让学生跟唱, 让学生在跟唱 过程中练习自身的五音, 然后不断的让学生进行训练, 学生训练到一定 程度, 就可以将歌词改成曲谱让学生再次深入的训练。教师在教学过程 中将主体地位交给学生, 加强学生在课堂中的视唱练耳训练, 可以通过 教师引导让学生的视唱练耳得到充分有效的东西提高。

\section{2 创设相应教学情境, 加强视唱练耳情感共鸣}

在音乐中蕴含着大量的情感, 可以说如果没有情感, 那就没有音乐, 音乐是一种情感的体现, 因此不管是在唱的时候需要唱出情感, 在听的时 候也需要倾听到其中蕴含的情感。基于此, 教师在视唱练耳教学过程中, 可以创设相应的教学情境, 在教学情境中加强情感共鸣, 让学生将视唱练 耳和教学情境相互结合, 从而增强学生视唱练耳的情感表达和感受能力。

比如在《高山流水志家园》这一课的教学过程中, 教师可以先为学 生讲解钟子期和伯牙的故事, 让学生明白高山流水的典故。然后再让学 生欣赏广陵散和流水两个曲子, 创设相应的教学情境, “假设你是伯牙或 者钟子期, 你遇到知已会产生一种怎样的感情, 哪一个曲子体现了这种 心情。” 然后学生就能明白知已相遇应该是喜悦高兴的、就能体会到流水 这首曲子, 而广陵散体现的就是知已难寻, 这样在视唱的时候学生也能
够表达出这种情感。通过相应教学情境创设, 让学生达到情感上的共鸣, 从而让学生的视唱练耳更具情感, 并进一步提高学生视唱练耳的水平。

\section{3 乐理知识和视唱练耳相结合, 提高学生整体音乐水平}

如果说视唱练耳教学能够让学生知道如何去唱音乐、如果去感受欣 赏音乐, 那么乐理知识就是整个视唱练耳教学乃至整个音乐教学的钥匙, 贯穿于视唱练耳的始终。但是在传统教学模式下, 教师对乐理知识和视 唱练耳这两个方面的教学没有充分有效的结合, 要么是忽略了乐理知识, 要么是忽略了视唱练耳。新课改下, 教师需要充分的将乐理知识和视唱 练耳教学相互结合, 从而提高学生整体音乐水平。

比如在《洗星海》这一课的教学过程中, 主要是介绍这一音乐家以 及欣赏他的作品《黄河大合唱》, 教师可以在欣赏《黄河大合唱》的时候 来加入一些乐理知识, 《黄河大合唱》里面有男生也有女生, 男生和女生 唱歌是不一样的, 这就是音色的不同, 然后其中有高音甚至低音, 最高 的音和最低的音之间就是音域, 还有一些音名、大调以及小调等等。通 过这样的乐理知识和视唱练耳结合, 可以让学生在练耳的时候了解整首 歌的基本构成, 也可以让学生在视唱的时候注意其中的乐理知识, 有利 于提高学生整理音乐水平。

综上所述, 视唱练耳课程是音乐学习的基础课程之一, 其能力的高 低能力引起音乐学习中的一系列的连锁反应, 对学生学习音乐有很大的 影响。为了提高学生视唱练耳的能力, 教师要尊重学生在课堂中的主体 地位, 加大学生课堂训练量, 从而在训练中促进学生视唱练耳。教师还 可以创设相应教学情境, 从而和视唱练耳形成情感上的共鸣, 从而让学 生更好的学习视唱练耳。教师需要将乐理知识和视唱练耳有效结合, 让 学生在充分理解乐理知识的基础上进行视唱练耳, 这样可以提高学生整 体音乐水平。

\section{[参考文献]}

[1]刘迎宾. 新高考下的高中音乐教学初探 [J]. 当代家庭教 育,2020(24):111.

[2]顾喜叶.高中音乐课堂师生互动教学模式探析[J].中学教学参 考,2020(24):16-17.

[3] 赵虹艳.核心素养背景下高中音乐鉴赏教学研究 [J]. 新课 程,2020(33):62. 